\title{
SOSIALISASI DAN PELATIHAN MODEL PEMBELAJARAN BAHASA INGGRIS BERBASIS PROYEK DALAM KONDISI PEMBELAJARAN JARAK JAUH
}

\author{
Ni Luh Putu Ning Septyarini Putri Astawa1), Ketut Queena Fredlina²), Ni Luh Suminiasih ${ }^{1)}$ \\ 1)Prodi Sistem Informasi, STMIK Primakara, Denpasar, Bali, Indonesia \\ ${ }^{2}$ Prodi Informatika, STMIK Primakara, Denpasar, Bali, Indonesia \\ Corresponding author:Ni Luh Putu Ning Septyarini Putri Astawa ${ }^{1}$ E-mail: ningseptyarini@ymail.com
}

Diterima 05 Oktober 2020, Direvisi 20 Oktober 2020, Disetujui 21 Oktober 2020

\begin{abstract}
ABSTRAK
Kegiatan pengabdian masyarakat ini bertujuan untuk menambah pengetahuan guru dalam proses pelaksanaan pembelajaran yang menarik bagi siswa .Tujuan dari kegiatan pengabdian ini adalah untuk memberikan sosialisasi serta penyuluhan tentang pelaksanaan pembelajaran berbasis proyek menggunakan teknologi di dalam kelas daring dalam kondisi pasca pandemi. Metode pengabdian yang digunakan adalah dengan metode ceramah,simulasi,dan praktik. Dalam pengabdian ini dilakukan pelatihan model pembelajaran khususnya dalam mata pelajaran Bahasa Inggris. Pada akhir proses kegiatan, diketahui bahwa peserta pelatihan menanggapi positif kegiatan ini. Hal ini dapat terlihat dari hasil observasi yang menunjukkan antusiasme peserta selama proses pelatihan berlangsung.
\end{abstract}

Keyword: project-based learning; pembelajaran jarak jauh; pasca pandemi.

\section{ABSTRACT}

This community service activity aims to increase teacher knowledge in the process of implementing learning that is attractive to students. The purpose of this service activity is to provide socialization and counseling about the implementation of project learning using bold technology in the classroom in postpandemic conditions. The service used is lecture,simulation, and practice methods. In this service ,learning model training is carried out, especially in English subjects. At the end of the activity, it was discovered that the training participants forgot about positive activities. This can be seen from the result of observations that show the enthusiasm of the participants during the process.

Keywords: project-based learning; long distance learning; post-pandemic

\section{PENDAHULUAN}

Abad 21 membawa tuntutan sendiri kepada kemampuan belajar yang harus dimiliki oleh siswa masa kini. Kemampuan belajar yang sebaiknya dimiliki oleh para generasi abad 21 menurut Harshbarger (2016) diantaranya adalah berfikir kritis, kreatif, komunikatif, serta baik dalam berkolaborasi bersama tim. Kemampuan tersebut atau yang biasa disebut dengan 4Cs Skills merupakan empat kemampuan yang dipercaya dapat menunjang kemampuan bertahan hidup seseorang di masa yang akan datang. Sehingga sebaiknya sebuah proses pembelajaran tidak hanya terfokus pada tujuan dari pembelajaran itu sendiri, namun juga dapat mengasah ke empat kemampuan tersebut.

Kemampuan belajar tersebut juga diharapkan untuk bisa selalu diasah walaupun dalam keadaan kondisi pembelajaran jarak jauh pasca pandemi. Studi yang bertujuan untuk mempersiapkan kemampuan guru dalam menyediakan media pembelajaran yang dapat mengasah kemampuan siswa dalam hal teknologi serta kemampuan abad 21 dilakukan juga telah sering dilakukan (Astawa \& Utami: 2020; Dewi, Putri, \& Wijaya: 2020). Studi tersebut mengungkapkan pentingnya peran guru dalam menyediakan media pembelajaran yang mampu memfasilitasi siswa digital native yang memiliki kebutuhan tersendiri terhadap pembelajaran yang aktif, menarik, efektif, efisien, serta tidak sarat teknologi.

Pembelajaran yang aktif diartikan sebagai kondisi pembelajaran yang dimana siswa memiliki keterikatan yang tinggi terhadapproses pembelajaran itu sendiri (Fayombo, 2012). Dalam hal ini, peran siswa menjadi kunci utama dalam menilai tingkat keberhasilan dari pembelajaran tersebut. Dapat dikatakan bahwa peran guru pada proses pembelajaran adalah lebih pada bagaimana merancang sebuah proses pembelajaran agar dapat menciptakan suasana belajar yang kondusif dan dapat membentuk keterikatan sendiri antara siswa serta proses pembelajaran yang terjadi di dalam kelas (Putri,2018).

Hal serupa juga tampaknya diatur 
dalam Standar Nasional Pendidikan Indonesia Nomor 19 Tahun 2005, Pasal 19, Ayat 1 yang menyatakan bahwa pembelajaran sebaiknya dapat tercipta dalam kondisi yang interaktif, menginspirasi, menyenangkan, serta menantang bagi siswa. Kata lain dari kondisi tersebut biasa disebut dengan PAKEM yang dimana menurut Rahmi (2018) merupakan singkatan dari Pembelajaran Aktif, Kreatif, Efektif dan Menyenangkan.

Salah satu model pembelajaran yang

dinyatakan mampu menciptakan kondisi pembelajaran tersebut di atas adalah metode pembelajaran berbasis proyek. Metode pembelajaran berbasis proyek adalah sebuah proses pembelajaran yang dimana dalam pengimplementasiannya dikelilingi oleh kegiatan penyelesaian proyek yang dimana siswa menggunakan proyek tersebut sebagai sarana untuk membentuk ilmu yang baru (Wajdi, 2017). Menurut The George Lucas Educational Foundation (2003) dalam mengimplementasikan pembelajaran berbasis proyek terdapat beberapa tahapan yang dapat dilakukan yaitu tahapan pemaparan masalah, perencanaan, penetapan target proyek, pengawasan, serta proses evaluasi.

Pengerjaan proyek dalam proses pembelajaran juga masih dapat dilaksanakan dalam kondisi pasca pandemi dengan menggunakan instrumen pembelajaran yang tepat (Kim \& Bonk, 2006 dalam Dhawan 2020). Teknologi adalah salah satu solusi yang dapat memfasilitasi kegiatan pembelajaran berbasis siswa agar tetap berjalan optimal. Kegiatan proyek dapat difasilitasi dengan berbagai jenis tingkatan teknologi, mulai dari penerapan teknologi dasar seperti pencarian di internet, pembuatan musik, film, video, dan lainnya (Lenz \& Adams, 2020).

Sayangnya kemampuan guru dalam membuat desain pembelajaran yang dapat menciptakan suasana belajar lebih menarik masih rendah (Leonard, 2016). Ditemukan bahwa dalam penelitiannya, Leonard menemuk an hampir $75 \%$ guru di Jakarta Indonesia tidak berhasil untuk mempersiapkan pembelajarannya dengan baik. Penyebab dari permasalahan ini adalah kurangnya pengetahuan guru tentang aplikasi metode pembelajaran yang lebih inovatif.

Hal serupa juga ditemukan oleh

Wibowo (2015) yang menyatakan bahwa rendahnya kompetensi guru yang disebabkan oleh minimnya kegiatan pelatihan yang dapat diikuti oleh para guru. Sehingga kurangnya akses guru untuk mendapatkan pembaharuan pengetahuan menyebabkan rendahnya pengetahuan guru tentang pelaksanaan proses pembelajaran yang menarik. Fakta tersebut di atas menjadi salah satu dasar pemikiran penulis untuk melakukan pelatihan model pembelajaran terutamanya dalam mata pelajaran Bahasa Inggris. Adapun model yang dibahas dalam pelatihan ini adalah model pembelajaran berbasis proyek, mengingat kelebihan yang dimiliki oleh model pembelajaran ini.

Adapun solusi yang ditawarkan dalam pengabdian ini adalah memberikan sosialisasi serta penyuluhan tentang pelaksanaan pembelajaran berbasis proyek menggunakan teknologi di dalam kelas daring dalam kondisi pasca pandemi. Dalam tujuannya untuk memperoleh hasil sesuai dengan yang diharapkan, terdapat 2 langkah kegiatan yang dilaksanakan, diantaranya (1) pendahuluan dan (2) proses pelaksanaan.

\section{METODE \\ Metode Penerapan Kegiatan}

1) Ceramah

Metode yang dimaksud adalah untuk memberikan sosialisasi serta pelatihan pelatihan tentang pelaksanaan pembelajaran berbasis proyek khususnya dalam pembelajaran Bahasa Inggris.

2) SimulasiMetode

Metode simulasi dilakukan agar dapat mempraktekan bagaimana pelaksanaan pembelajaran berbasis proyek dengan menggunakan teknologi di dalam kelas daring pasca pandemi. Dalam tahapan ini,pemateri melakukan simulasi terhadap pelaksanaan pembelajaran berbasis proyek,sehingga para peserta dapat mengamati dengan seksama

3) Praktik

Peserta terdiri dari 177 orang guru yang tergabung menjadi anggota grup webinar milik Relawan TIK Provinsi Bali melakukan praktikmodel pembelajaran berbasis proyek dalam mata pembelajaran Bahasa Inggris secara daring dengan menggunakan streaming platform yaitu Youtube dan juga Skype. Para peserta merancang kegiatan pembelajaran berbasis proyek dalam pembelajaran daring. Pada akhir proses pelatihan, para peserta mampu membuat draft rancangan yang kemudian diberikan oleh pemateri

\section{Peserta Kegiatan}

Adapun peserta dari kegiatan ini adalah 117 guru SD, SMP, dan SMA/SMK/ sederajat yang tersebar di seluruh Indonesia. Para guru tersebut juga tergabung menjadi anggota grup webinar milik Relawan TIK ProvinsiBali.

\section{Waktu dan Tempat Kegiatan}

Kegiatan PKM ini dilaksanakan pada masa pandemi Covid-19 yang menyebabkan harus dilaksanakan secara daring. Adapun streaming platform yang digunakan adalah channel YouTube milik RTIK Bali dan juga 
Skype. Kegiatan ini dilaksanakan pada bulan Juli 2020.

\section{HASIL DAN PEMBAHASAN \\ Kegiatan Pendahuluan}

Dalam melakukan proses perencanaan ada beberapa tahap yang dilakukan.Tahap pertama yaitu tahap perencanaan. Tahap perencanaan dilakukan dengan cara menyusun berbagai hal. Perlu diingatkan bahwa kegiatan ini dilakukan pada saat adanya pandemi Covid19 yang menyebabkan kegiatan ini harus dilaksanakan secara daring, sehingga dipilihlah YouTube dan juga Skype sebagai media streaming kepada peserta di kegiatan ini.

Adapun beberapa hal yang disiapkan antara lain materi, jadwal kegiatan, moderator,platform dan koneksi yang baik yang akan digunakan dalam proses pelatihan. Kedua adalah tahapan pendekatan, dimana pada tahap ini tim pengabdian melakukan diskusi dengan beberapa guru khususnya wilayah Bali untuk mencari tahu kebutuhan serta teknis pelaksanaan pelatihan.Selain Itu

,juga dilaksanakan pendekatan kepada Relawan TIK Provinsi Bali sebagai komunitas yang menjembatani kegiatan ini.

\section{Kegiatan Pelaksanaan}

Tahapan pelaksanaan kegiatan ini diawali dengan sosialisasi dan pengenalan terhadap pembelajaran daring berbasis proyek khususnya pada pembelajaran Bahasa Inggris dan peserta akan akan menyimak simulasi pembelajaran berbasis proyek yang diikuti praktik mandiri dari masing-masing peserta yang mengikuti program pengabdian masyarakat ini. Pelaksanaan kegiatan dapat dilihat dari Gambar 1 sampai Gambar 4.

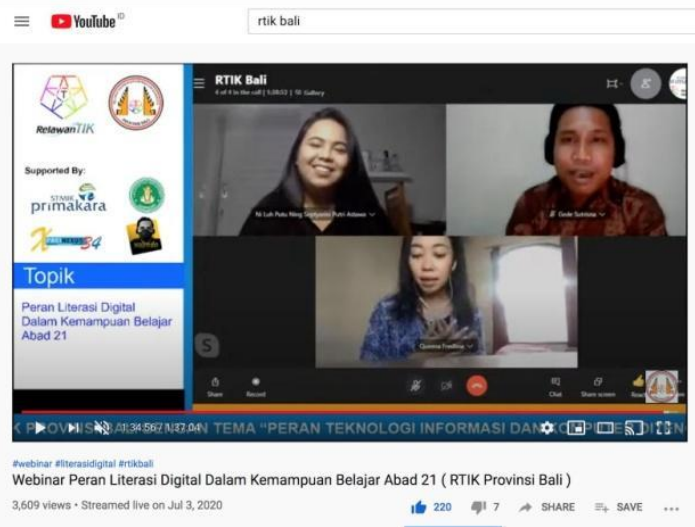

Gambar 1. Pelaksanaan Kegiatan

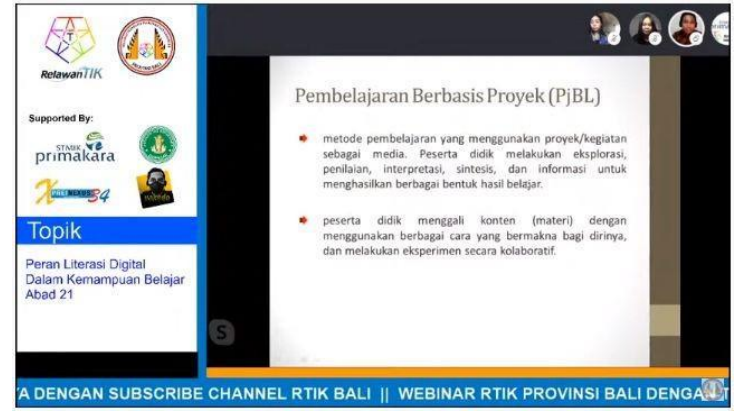

Gambar 2. Penjelasan tentang pembelajaran berbasis proyek

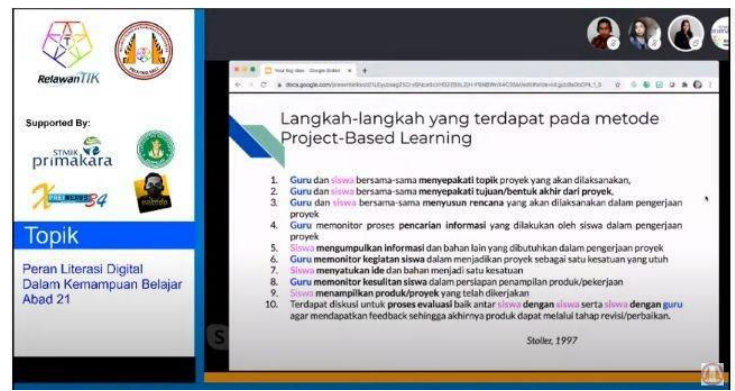

Gambar 3. Pengenalan metode Pembelajaran berbasis proyek

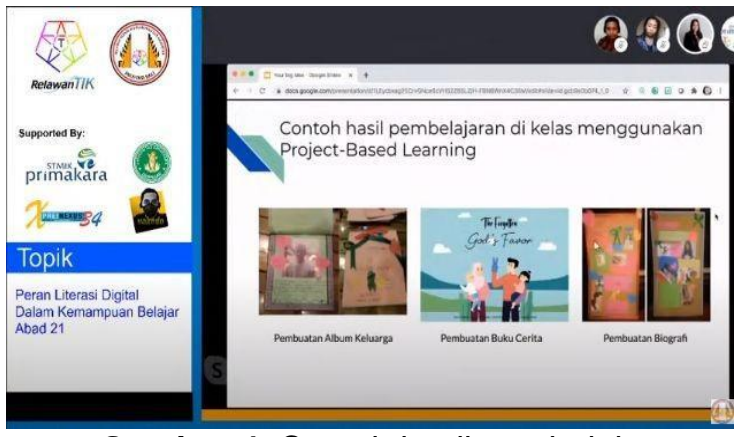

Gambar 4. Contoh hasil pembelajaran

Dalam pelatihan ini telah memberikan manfaat bagi guru atau pendidikan yang telah bergabung dalam hal pengetahuan dan keterampilan dalam penggunaan model pembelajaran daring berbasis proyek khususnya dalam pembelajaran bahasa inggris agar pembelajaran dalam tujuannya untuk meningkatkan keterikatan siswa dalam proses belajar.Para guru dan tenaga pendidik lainnya yang telah menjadi peserta sudah mengikuti kegiatan dengan baik.Antusias peserta yang mengikuti pelatihan juga sangat bagus. Hal ini dapat diketahui dari hasil observasi yang menyatakan aktifnya peserta dalam berdiskusi,bertanya, dan menjawab di kolom live chat YouTube yang tersedia.

Selain itu,di akhir pelaksanaan kegiatan para guru juga mendapat kesempatan untuk mempraktekkan pengetahuan yang telah diperoleh. Para peserta membuat draft kegiatan pembelajaran berbasis proyek yang disesuaikan dengan keadaan kelas masing- 
masing yang dimiliki oleh peserta pelatihan.

Harapan dari pelaksanaan kegiatan ini agar dapat melatih peserta untuk terus meningkatkan pengetahuan dan keterampilan untuk berinovasi dan bisa beradaptasi dengan situasi pandemi. Para pelaksana kegiatan berharap model pembelajaran yang dijelaskan bisa meningkatkan kualitas mengajar guru dalam pembelajaran daring berbasis proyek.

\section{SIMPULAN DAN SARAN}

Pelaksanaan kegiatan pelatihan model pembelajaran Bahasa Inggris berbasis proyek untuk kondisi pembelajaran jarak jauh sudah dilaksanakan. Para peserta pelatihan mampu memahami dan membuat rancangan bagaimana model pembelajaran berbasis proyek sehingga harapannya dapat diterapkan dalam kelas masing-masing. Tanggapan peserta terhadap pelaksanaan kegiatan ini sudah baik, hal ini dapat dilihat dari antusiasme peserta dalam memberikan respon diskusi dengan menjawab maupun bertanya.Selain itu para peserta mendapatkan kesempatan untuk merancang kegiatan pembelajaran daring berbasis proyek yang dimana menunjukkan pemahaman peserta terhadap materi yang telah dijelaskan oleh pemateri Selanjutnya penulis berharap agar pelatihan-pelatihan yang bermanfaat bagi para guru dan pendidik dapat diadakan secara rutin agar masing-masing pihak dapat menjalin relasi yang saling bersinergi dan dapat memberikan pendidikan yang berkualitas di indonesia

\section{DAFTAR RUJUKAN}

Astawa, N. L. P. N. S. P., \& Utami, N. W. . (2020). Pelatihan Pembuatan Buku Cerita Digital Sederhana Sebagai Bahan Ajar dalam Kondisi New Normal . Jurnal Karya Abdi Masyarakat, 4(1), 143-147. Retrieved from https://www.onlinejournal.unja.ac.id/JKAM/article/view/98 32

Dewi, G. A. P. M. K., Putri, N. L. P. N. S., \&

Wijaya, I. N. Y. A. (2020). Aplikasi Augmented Reality Pada Buku Cerita Bilingual "The Shrimp And The Crab". Paedagoria: Jurnal Kajian, Penelitian dan Pengembangan Kependidikan, 11(2), 163-171.

Dhawan, S. (2020). Online learning: A panaceainthetimeofCOVID-19 crisis. Journal of Educational Technology Systems, 49(1), 5-22.

Fayombo, G. A. (2012). Active learning strategies and student learning outcomes among some university students in Barbados. Journal of
Educational and Social Research, 2(9),79-79.

Harshbarger, R. (2016). Learning in the $21^{\text {st }}$ Century: A Study Addressing Educational Trends and Implications. Electronic Theses and Dissertations. 5043. Retrieved from:

http://stars.library.ucf.edu/etd/5043

Lenz, B. \& Adams, L. (2020). This Teachable Moment - Engaging Our KidsIn The Joy Of Learning. USA: PBLWork

Leonard, L. (2016). Kompetensi tenaga pendidik di Indonesia: Analisis dampak rendahnya kualitas SDM guru dan solusi perbaikannya. Formatif: Jurnal IImiah Pendidikan MIPA, 5(3).

Putri, N. L. P. N. S. (2018). The Impact Of Project-Based Instruction On Students' Engagement And Speaking Skills. Widya Accarya, 9(2).

Rahmi, J. (2018). Pengaruh Strategi Pakem (Pembelajaran Aktif Kreatif Efektif Dan Menyenangkan) Berbasis Permainan Teka-Teki Terhadap Hasil Belajar Siswa Kelas V Melalui Mata Pelajaran Ips Di Mis Nurul Fadhilah Bandar Setia Tahun Ajaran 2017/2018 (Doctoral dissertation, Universitas Islam Negeri Sumatera Utara Medan).

The George Lucas Educational Foundation (2003). Diakses pada 23 April 2015, dari: https://prezi.com/ky_fz_eah7rd/ steps-for-project-based-learning/.

Wajdi, F. (2017). Implementasi project based learning (PBL) dan penilaian autentik dalam pembelajaran drama indonesia. Jurnal Pendidikan Bahasa dan Sastra UPI, 17(1), 86-101.

Wibowo, C. H. (2015). Problematika Profesi Guru Dan Solusinya Bagi Peningkatan Kualitas Pendidikan di MTs. Negeri Nguntoronadi Kabupaten Wonogiri (Doctoral dissertation, IAINSURAKARTA). 